\title{
Long-Term Anatomical and Functional Outcome of Three Intravitreal Bevacizumab Injections for Persistent Macular Edema after Idiopathic Macular Epiretinal Membrane Peeling
}

\author{
Yo-Chen Chang a, c Chia-Ching Lin ${ }^{c}$ Wen-Chuan Wub,c \\ Departments of Ophthalmology at ${ }^{a}$ Kaohsiung Municipal Hsiao-Kang Hospital and \\ ${ }^{\mathrm{b}}$ School of Medicine, Kaohsiung Medical University, and ${ }^{\mathrm{C} K a o h s i u n g ~ M e d i c a l ~ U n i v e r s i t y ~}$ \\ Hospital, Kaohsiung, Taiwan
}

\section{Key Words}

Antivascular endothelial growth factor · Epiretinal membrane $\cdot$ Macular edema

\begin{abstract}
Purpose: The aim of this study was to investigate the effect of three consecutive intravitreal bevacizumab injections (IVB) on long-term outcome for patients with macular edema after epiretinal membrane (ERM) removal. Methods: All patients in both the treatment and control groups had persistent macular edema 3 months after ERM removal. The patients in the treatment group received three consecutive IVB in an interval of approximately 4 weeks. The main outcome measures included logarithm of the minimum angle of resolution (logMAR) bestcorrected visual acuity (BCVA) and central foveal thickness (CFT) determined by optical coherence tomography. Results: Two weeks after the first IVB, CFT decreased significantly by 24.1 $\pm 4.2 \mu \mathrm{m}$ in the treatment group versus $4.2 \pm 2.1 \mu \mathrm{m}$ in the control group $(p<0.001)$. However, the mean reduction in CFT after 12 months did not differ significantly between the two groups $(35.2 \pm 4.9$ vs. $33.7 \pm 4.6 \mu \mathrm{m}, \mathrm{p}=0.824)$. No significant differences were found for logMAR BCVA between the two groups at each follow-up. Conclusion: IVB could significantly decrease macular edema 2 months after the initial injection but failed to make significant differences in final CFT and logMAR BCVA.

(C) 2014 S. Karger AG, Basel
\end{abstract}

Y.-C.C. and C.-C.L. contributed equally to this article. This paper was presented in part at the annual meeting of the Ophthalmological Society of Taiwan in November 2009, Taipei, Taiwan. 


\section{Introduction}

Idiopathic macular epiretinal membrane (ERM) is a cellular avascular membrane, which occurs during the process of posterior vitreous detachment (PVD) [1]. Pars plana vitrectomy (PPV) with membrane peeling, which was first described by Machemer [2] in 1978, has become a well-established surgical procedure for the removal of ERM with favorable results. Surgical removal of the membranes in patients with significant symptoms can improve visual acuity and reduce metamorphopsia in approximately $70-90 \%$ of the cases, whereas others do not benefit from this procedure [3-5]. Bevacizumab, a humanized full-length antibody against all isoforms of vascular endothelial growth factor (VEGF) A, has been successfully used off-label for the management of neovascular age-related macular degeneration and macular edema from various etiologies [6-9]. However, in the literature review, there is only one short-term follow-up study regarding single intravitreal bevacizumab injection (IVB) for persistent macular edema after ERM removal, with no beneficial effects on visual improvement [10]. Therefore, in our present study, we enrolled patients who underwent vitrectomy and removal of ERM, but macular edema showed no tendency to resolve 3 months after surgery. The purpose of this study is to determine the long-term efficacy of three consecutive IVB for treating persistent macular edema after complete removal of idiopathic ERM.

\section{Patients and Methods}

\section{Study Population}

This study is a retrospective, non-randomized study including patients who were diagnosed as idiopathic ERM between January 2008 and December 2010. The described research adhered to the tenets of the Declaration of Helsinki 1964. The treating physician (W.-C.W.) is a retinal specialist experienced in ERM and cataract surgeries as well as intravitreal injection. All patients previously underwent a standard three-port PPV assisted with triamcinolone and membrane peeling using high-magnification viewing and intraocular forceps. PVD was induced with active suction of ocutome over the optic disc if the PVD was not already present. Concomitant cataract surgery was performed on phakic patients. After surgery, tobradex eye drops $(0.3 \%$ tobramycin and $0.1 \%$ dexamethasone) 4 times daily and mydriacyl $(0.5 \%$ tropicamide) 3 times daily were administered to all patients for 2 weeks. There were no significant complications such as retinal detachment, iatrogenic macular hole, postoperative vitreous hemorrhage or endophthalmitis that affected visual outcome during or after the surgeries.

Three months after PPV, patients who met the following criteria were suggested for IVB treatment: (1) presence of a macular edema $\geq 250 \mu \mathrm{m}$ as detected by optical coherence tomography (OCT) 3 months after complete idiopathic ERM removal by PPV, and (2) best-corrected visual acuity (BCVA) $<20 / 50$ after surgery.

Patients with preexisting ocular diseases (i.e., glaucoma, high myopia, retinal vascular occlusion, chronic inflammatory or neoplastic disorders) were excluded, as were those with systemic diseases (diabetes or uncontrolled hypertension).

\section{Methods of Intervention and Follow-Up}

The decision to treat with IVB was made by the eligible patients after a complete discussion of the risks, benefits and alternatives to treatment. If the patients decided to proceed with IVB therapy, they signed a consent form before treatment. In the treatment group, each patient received their first intravitreal injection of bevacizumab $(0.05 \mathrm{ml} / 1.25 \mathrm{mg})$ approximately 3 


\begin{tabular}{|c|c|c|c|}
\hline \multicolumn{4}{|l|}{ Ophthalmologica Extra 2014;1:1-8 } \\
\hline \multicolumn{2}{|l|}{ DOI: 10.1159/000360185 } & \multicolumn{2}{|c|}{$\begin{array}{l}\text { (c) } 2014 \text { S. Karger AG, Basel } \\
\text { www.karger.com/opx }\end{array}$} \\
\hline \multicolumn{4}{|c|}{$\begin{array}{l}\text { Chang et al.: Long-Term Anatomical and Functional Outcome of Three IVB for } \\
\text { Persistent Macular Edema after Idiopathic Macular ERM Peeling }\end{array}$} \\
\hline & $\begin{array}{l}\text { Treatment } \\
\text { group }\end{array}$ & $\begin{array}{l}\text { Control } \\
\text { group }\end{array}$ & $\begin{array}{l}\mathrm{p} \\
\text { value }\end{array}$ \\
\hline Number of patients & 25 & 23 & \\
\hline Male:female & $12: 13$ & $12: 11$ & 0.990 \\
\hline Age, years & $62.8 \pm 5.8$ & $61.5 \pm 5.7$ & 0.460 \\
\hline Right eye:left eye & $11: 14$ & $11: 12$ & 0.790 \\
\hline \multicolumn{4}{|l|}{ Lens status pre-PPV } \\
\hline Phakic & 13 & 10 & 0.555 \\
\hline Pseudophakic & 12 & 13 & \\
\hline \multicolumn{4}{|l|}{ Lens status 3 months after PPV } \\
\hline Phakic & 0 & 0 & 1.0 \\
\hline Pseudophakic & 25 & 23 & \\
\hline \multicolumn{4}{|l|}{ BCVA (logMAR) } \\
\hline Pre-PPV & $0.88 \pm 0.33$ & $0.87 \pm 0.35$ & 0.919 \\
\hline Three months after PPV & $0.55 \pm 0.33$ & $0.54 \pm 0.36$ & 0.964 \\
\hline \multicolumn{4}{|l|}{$\mathrm{CFT}, \mu \mathrm{m}$} \\
\hline Pre-PPV & $431.0 \pm 88.3$ & $433.9 \pm 80.5$ & 0.904 \\
\hline Three months after PPV & $334.5 \pm 63.4$ & $331.0 \pm 56.2$ & 0.911 \\
\hline Interval from PPV to IVB, weeks & $13.5 \pm 1.7$ & $\mathrm{~N} / \mathrm{A}$ & \\
\hline
\end{tabular}

Table 1. Demographic data

months after PPV. Postoperatively, gentamycin eye drops were administered 4 times daily for 1 week. Additional injections were given to each patient in the treatment group at an interval of approximately 1 month. A total of three consecutive injections were performed on each patient in the treatment group. In the meantime, no other interventions were performed on patients in the control group.

For better comparison of all parameters between the treatment and control groups, we defined 'baseline' as the time point that was 3 months after PPV. After the start of the followup period, the patients were seen at $0.5,1,2$, and 3 months and then every 3 months until 12 months after baseline. To evaluate the effects and safety of treatment, all recruited patients underwent comprehensive ophthalmic examinations including OCT, visual acuity by Snellen charts, slit-lamp biomicroscopy, Goldmann applanation tonometry and ophthalmoscopy at each follow-up visit. Retinal thickness measurements were performed using the OCT Stratus III device (Carl Zeiss Meditech, Dublin, Calif., USA). In all measurements, the central foveal thickness (CFT) was assessed within a 1-mm diameter circle in the central macula. For better comparison of visual acuity between the groups, the visual acuity by Snellen chart was converted to the logarithm of the minimum angle of resolution (logMAR) at baseline and each follow-up visit.

\section{Statistical Analysis}

All data were statistically analyzed by Student's t test, the $\chi^{2}$ test or Pearson correlation test using SPSS statistical software (version 10.0; SPSS Inc., Chicago, Ill., USA). A p value of $\leq 0.05$ was considered statistically significant.

\section{Results}

\section{Baseline Demographic Data}

During the period of 2 years, a total of 150 eyes of 140 patients with idiopathic ERM who underwent PPV and ERM peeling were reviewed. According to the inclusion criteria, there were 48 eyes of 48 patients included in this study. Table 1 shows the participants' baseline 
Chang et al.: Long-Term Anatomical and Functional Outcome of Three IVB for

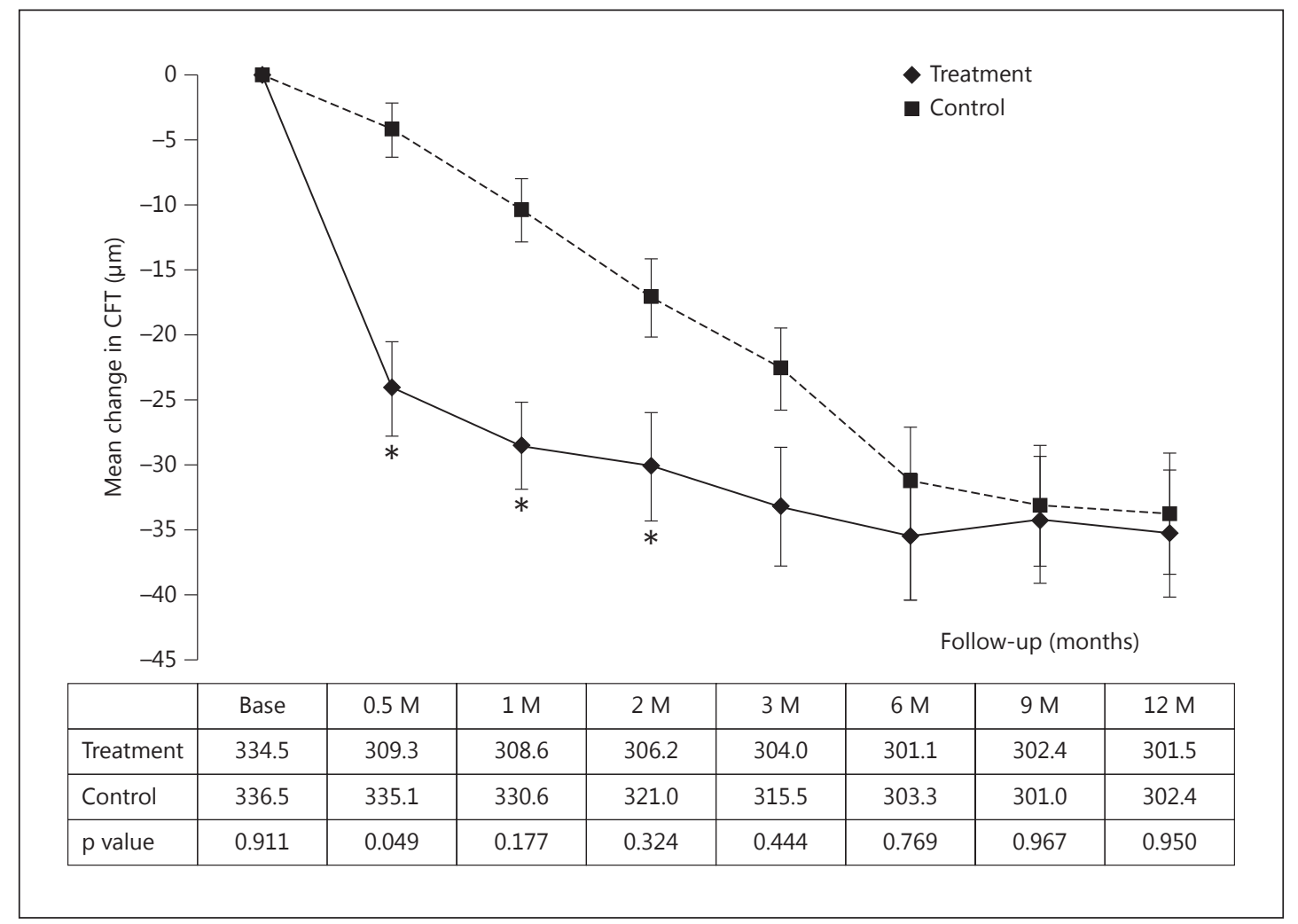

Fig. 1. Temporal change of CFT after IVB. The reduction in CFT differed significantly between the two groups during the first $0.5,1$ and 2 months after IVB. The mean CFT remained stable 6 months after IVB in the treatment group. In the control group, the mean reduction in CFT increased gradually during the 6 postoperative months and remained stable thereafter. The table below the graph shows the absolute values of the mean CFT for each follow-up visit. Base = Baseline; $\mathrm{M}=$ months; ${ }^{*} \mathrm{p} \leq 0.05$ compared between the groups at each follow-up visit.

demographics. Twenty-five eyes of 25 patients and 23 eyes of 23 controls were enrolled and followed-up for at least 12 months after baseline (i.e., 15 months after PPV). The pre-PPV BCVA was $0.88 \pm 0.33$ and $0.87 \pm 0.35 \log$ MAR in the treatment and control groups, respectively (table 1). Thirteen eyes in the treatment group and 10 eyes in the control group underwent combined surgery of PPV, phacoemulsification and intraocular lens implantation. Others with pseudophakia (12 eyes in the treatment group and 13 eyes in the control group) had PPV only. The pre-PPV CFT by OCT was $431 \pm 88$ and $434 \pm 80 \mu \mathrm{m}$ in the treatment and control groups, respectively (table 1). In the treatment group, the mean interval from PPV to IVB was $13.5 \pm 1.7$ weeks (table 1 ).

\section{Temporal Change of CFT}

The mean CFT at baseline was $334.5 \pm 63.4 \mu \mathrm{m}$ for the treatment group and $336.5 \pm 56.2$ $\mu \mathrm{m}$ for the control group $(\mathrm{p}=0.911)$. All patients in the treatment group received three consecutive IVB with a minimal interval of 4 weeks (range: $4-6$ ). Compared to baseline, the mean CFT at 0.5 months after IVB decreased rapidly by $24.1 \pm 4.2$ to $309.3 \pm 57 \mu \mathrm{m}$ for the treatment group and by only $4.2 \pm 2.1$ to $335.1 \pm 56.4 \mu \mathrm{m}$ for the control group $(\mathrm{p}<0.01)$. At 6 months, the mean CFT decreased by $35.5 \pm 4.9$ to $304 \pm 49.3 \mu \mathrm{m}$ for the treatment group and by $31.2 \pm 4.1$ to $303.3 \pm 52.5 \mu \mathrm{m}$ for the control group. Six months after baseline, the reduction in CFT became stable in both groups. At the last follow-up visit, the mean CFT was 


\section{Ophthalmologica}

Chang et al.: Long-Term Anatomical and Functional Outcome of Three IVB for

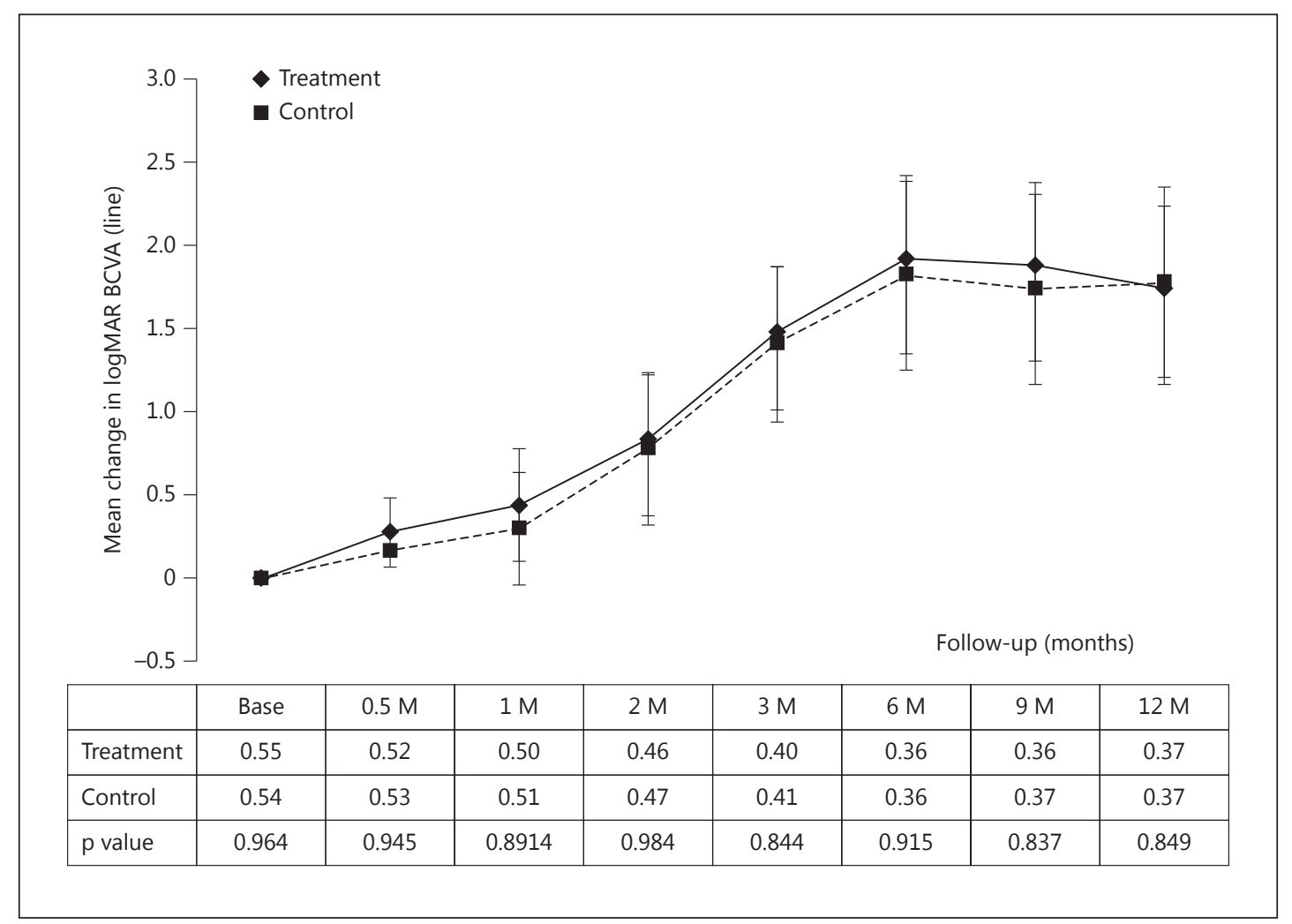

Fig. 2. Temporal change of BCVA by line after IVB. In both groups, BCVA improved gradually during the first 6 months after baseline and remained stable thereafter. There were no significant differences in BCVA line improvement between the treatment and control groups at baseline and each follow-up visit. The table below the graph shows the absolute value of the mean logMAR BCVA for each follow-up visit. Base = Baseline; $M=$ months; ${ }^{*} \mathrm{p} \leq 0.05$ compared to baseline.

decreased by $35.2 \pm 4.9$ to $301.5 \pm 47.7 \mu \mathrm{m}$ for the treatment group and by $33.7 \pm 4.6$ to 302.4 $\pm 52.0 \mu \mathrm{m}$ for the control group. The mean reduction in CFT differed significantly between the treatment and control groups at 0.5, 1 and 2 months after baseline $(\mathrm{p}<0.05)$. Figure 1 shows the mean reduction in CFT over the course after IVB.

\section{Temporal Change of Visual Acuity}

At baseline, the mean BCVA was $0.55 \pm 0.33$ and $0.54 \pm 0.36 \operatorname{logMAR}$ in the treatment and control groups, respectively ( $p=0.964)$. In both groups, the BCVA improved gradually after baseline. At 1 month, the mean BCVA was increased by $0.44 \pm 0.34$ and $0.30 \pm 0.33$ lines from baseline in the treatment and control groups, respectively $(\mathrm{p}=0.779)$. At 6 months, the mean BCVA was increased by $1.92 \pm 0.50$ and $1.83 \pm 0.57$ lines from baseline in the treatment and control groups, respectively ( $\mathrm{p}=0.902)$. Six months after baseline, the line improvement of BCVA became stable in both groups. At 12 months, the mean BCVA was increased by $1.74 \pm$ 0.51 and $1.78 \pm 0.56$ lines from baseline in the treatment and control groups, respectively $(\mathrm{p}=0.955)$. At 12 months, the mean BCVA improved to $0.37 \pm 0.15$ and $0.36 \pm 0.17 \operatorname{logMAR}$ in the treatment and control groups, respectively $(\mathrm{p}=0.849)$. The logMAR BCVAs and line improvement did not differ significantly at $0.5,1,2,3,6,9$ and 12 months after treatment between the two groups. Figure 2 illustrates the line improvement in BCVA over the course of the study. 
Table 2. Correlations between BCVA and CFT in the treatment group $(n=25)$

\begin{tabular}{llllllllll}
\hline & BCVA $_{\text {Base }}$ & BCVA $_{0.5 \mathrm{M}}$ & BCVA $_{1 \mathrm{M}}$ & $\mathrm{BCVA}_{2 \mathrm{M}}$ & BCVA $_{3 \mathrm{M}}$ & BCVA $_{6}$ & BCVA $_{9}$ & BCVA $_{12 \mathrm{M}}$ \\
\hline CFT $_{\text {Base }}$ & $\mathrm{r}=0.7951$ & $\mathrm{r}=0.8126$ & $\mathrm{r}=0.8371$ & $\mathrm{r}=0.7846$ & $\mathrm{r}=0.8234$ & $\mathrm{r}=0.7086$ & $\mathrm{r}=0.6393$ & $\mathrm{r}=0.6761$ \\
& $\mathrm{p}<0.0001$ & $\mathrm{p}<0.0001$ & $\mathrm{p}<0.0001$ & $\mathrm{p}<0.0001$ & $\mathrm{p}<0.0001$ & $\mathrm{p}<0.0001$ & $\mathrm{p}=0.0006$ & $\mathrm{p}=0.0002$ \\
\hline $\mathrm{CFT}_{0.5 \mathrm{M}}$ & & $\mathrm{r}=0.7784$ & $\mathrm{r}=0.8128$ & $\mathrm{r}=0.7688$ & $\mathrm{r}=0.8151$ & $\mathrm{r}=0.7089$ & $\mathrm{r}=0.6396$ & $\mathrm{r}=0.6761$ \\
& & $\mathrm{p}<0.0001$ & $\mathrm{p}<0.0001$ & $\mathrm{p}<0.0001$ & $\mathrm{p}<0.0001$ & $\mathrm{p}<0.0001$ & $\mathrm{p}=0.0006$ & $\mathrm{p}=0.0002$ \\
\hline $\mathrm{CFT}_{1 \mathrm{M}}$ & & $\mathrm{r}=0.7940$ & $\mathrm{r}=0.7634$ & $\mathrm{r}=0.8085$ & $\mathrm{r}=0.7029$ & $\mathrm{r}=0.6370$ & $\mathrm{r}=0.6699$ \\
& & & $\mathrm{p}<0.0001$ & $\mathrm{p}<0.0001$ & $\mathrm{p}<0.0001$ & $\mathrm{p}<0.0001$ & $\mathrm{p}=0.0006$ & $\mathrm{p}=0.0002$ \\
\hline $\mathrm{CFT}_{2 \mathrm{M}}$ & & & $\mathrm{r}=0.7407$ & $\mathrm{r}=0.7887$ & $\mathrm{r}=0.6835$ & $\mathrm{r}=0.6267$ & $\mathrm{r}=0.6529$ \\
& & & $\mathrm{p}<0.0001$ & $\mathrm{p}<0.0001$ & $\mathrm{p}=0.0002$ & $\mathrm{p}=0.0008$ & $\mathrm{p}=0.0004$ \\
\hline $\mathrm{CFT}_{3 \mathrm{M}}$ & & & & $\mathrm{r}=0.7748$ & $\mathrm{r}=0.6759$ & $\mathrm{r}=0.6140$ & $\mathrm{r}=0.6428$ \\
& & & & $\mathrm{p}<0.0001$ & $\mathrm{p}=0.0002$ & $\mathrm{p}=0.0011$ & $\mathrm{p}=0.0005$ \\
\hline $\mathrm{CFT}_{6 \mathrm{M}}$ & & & & & $\mathrm{r}=0.6775$ & $\mathrm{r}=0.6014$ & $\mathrm{r}=0.6398$ \\
& & & & & $\mathrm{p}=0.0002$ & $\mathrm{p}=0.0015$ & $\mathrm{p}=0.0006$ \\
\hline $\mathrm{CFT}_{9 \mathrm{M}}$ & & & & & & $\mathrm{r}=0.6112$ & $\mathrm{r}=0.6449$ \\
& & & & & & $\mathrm{p}=0.0012$ & $\mathrm{p}=0.0005$ \\
\hline $\mathrm{CFT}_{12 \mathrm{M}}$ & & & & & & & $\mathrm{r}=0.6509$ \\
& & & & & & & & $\mathrm{p}=0.0004$ \\
\hline
\end{tabular}

Base = Baseline; $\mathrm{M}=$ months; $\mathrm{r}$ = Pearson correlation coefficient.

Table 3. Correlations between BCVA and CFT in the control group $(n=23)$

\begin{tabular}{|c|c|c|c|c|c|c|c|c|}
\hline & BCVA $_{\text {Base }}$ & $\mathrm{BCVA}_{0.5 \mathrm{M}}$ & $\mathrm{BCVA}_{1 \mathrm{M}}$ & $\mathrm{BCVA}_{2 \mathrm{M}}$ & $\mathrm{BCVA}_{3 \mathrm{M}}$ & $\mathrm{BCVA}_{6 \mathrm{M}}$ & $\mathrm{BCVA}_{9 \mathrm{M}}$ & $\mathrm{BCVA}_{12 \mathrm{M}}$ \\
\hline $\mathrm{CFT}_{\text {Base }}$ & $\begin{array}{l}r=0.5713 \\
p=0.0044\end{array}$ & $\begin{array}{l}r=0.5564 \\
p=0.0058\end{array}$ & $\begin{array}{l}r=0.6666 \\
p=0.0005\end{array}$ & $\begin{array}{l}r=0.5504 \\
p=0.0065\end{array}$ & $\begin{array}{l}r=0.5795 \\
p=0.0038\end{array}$ & $\begin{array}{l}r=0.6316 \\
p=0.0015\end{array}$ & $\begin{array}{l}r=0.6316 \\
p=0.0012\end{array}$ & $\begin{array}{l}r=0.6525 \\
p=0.0007\end{array}$ \\
\hline $\mathrm{CFT}_{0.5 \mathrm{M}}$ & & $\begin{array}{l}r=0.5425 \\
p=0.0075\end{array}$ & $\begin{array}{l}r=0.6613 \\
p=0.0006\end{array}$ & $\begin{array}{l}r=0.5456 \\
p=0.0071\end{array}$ & $\begin{array}{l}r=0.5719 \\
p=0.0044\end{array}$ & $\begin{array}{l}r=0.6269 \\
p=0.0014\end{array}$ & $\begin{array}{l}r=0.6222 \\
p=0.0015\end{array}$ & $\begin{array}{l}r=0.6517 \\
p=0.0008\end{array}$ \\
\hline $\mathrm{CFT}_{1 \mathrm{M}}$ & & & $\begin{array}{l}r=0.6211 \\
p=0.0015\end{array}$ & $\begin{array}{l}r=0.5100 \\
p=0.0129\end{array}$ & $\begin{array}{l}r=0.5350 \\
p=0.0085\end{array}$ & $\begin{array}{l}r=0.6087 \\
p=0.0021\end{array}$ & $\begin{array}{l}r=0.5929 \\
p=0.0029\end{array}$ & $\begin{array}{l}r=0.6297 \\
p=0.0013\end{array}$ \\
\hline $\mathrm{CFT}_{2 \mathrm{M}}$ & & & & $\begin{array}{l}r=0.5134 \\
p=0.0122\end{array}$ & $\begin{array}{l}r=0.5395 \\
p=0.0079\end{array}$ & $\begin{array}{l}r=0.6100 \\
p=0.0020\end{array}$ & $\begin{array}{l}r=0.5860 \\
p=0.0033\end{array}$ & $\begin{array}{l}r=0.6279 \\
p=0.0013\end{array}$ \\
\hline $\mathrm{CFT}_{3 \mathrm{M}}$ & & & & & $\begin{array}{l}r=0.5017 \\
p=0.0147\end{array}$ & $\begin{array}{l}r=0.5822 \\
p=0.0036\end{array}$ & $\begin{array}{l}r=0.5669 \\
p=0.0048\end{array}$ & $\begin{array}{l}r=0.5958 \\
p=0.0027\end{array}$ \\
\hline $\mathrm{CFT}_{6 \mathrm{M}}$ & & & & & & $\begin{array}{l}r=0.5793 \\
p=0.0038\end{array}$ & $\begin{array}{l}r=0.5583 \\
p=0.0056\end{array}$ & $\begin{array}{l}r=0.5792 \\
p=0.0038\end{array}$ \\
\hline $\mathrm{CFT}_{9 \mathrm{M}}$ & & & & & & & $\begin{array}{l}r=0.5696 \\
p=0.0046\end{array}$ & $\begin{array}{l}r=0.5914 \\
p=0.0030\end{array}$ \\
\hline $\mathrm{CFT}_{12 \mathrm{M}}$ & & & & & & & & $\begin{array}{l}r=0.5698 \\
p=0.0045\end{array}$ \\
\hline
\end{tabular}

Base = Baseline; $\mathrm{M}=$ months; $\mathrm{r}=$ Pearson correlation coefficient. 


\section{Correlations between Visual Acuity and CFT}

The changes in CFT and BCVA followed a similar course at each follow-up visit in both groups. The BCVA and CFT were well correlated at baseline and each follow-up visit in both groups $(\mathrm{p}<0.01)$. The detailed data are summarized in tables 2 and 3.

During the follow-up of the patients in the treatment group, no thromboembolic events or deaths occurred. No intraocular complication occurred either.

\section{Discussion}

PPV and membrane peeling has been proven an effective surgical procedure for VA improvement in patients with ERM $[4-6,11,12]$. However, studies of long-term follow-up after surgery have indicated that visual improvement and resolution of macular edema may take up to 12 months or longer to reach maximum improvement. In addition, residual macular edema after the removal of ERM is quite common [13-16]. In order to reduce postoperative residual macular edema, some authors use intravitreal injection of triamcinolone acetonide (IVTA) after successful removal of ERM $[12,14]$. A short-term non-comparative study indicated an increase in visual acuity and a marked decrease in CFT during the first postoperative week with further functional and anatomical improvement over a 6-month period [12]. However, a long-term comparative study demonstrated no significant differences between patients undergoing ERM removal with or without IVTA, but IVTA increased the risk of high intraocular pressure that required medication [14].

In our study, IVB significantly reduced CFT $0.5,1$ and 2 months after the first bevacizumab injection. However, there was no concomitant better visual improvement observed in the treatment group. The possible explanation for this inconsistency may be due to the multifactorial pathogenesis of ERM. It is widely believed that idiopathic ERM is produced by retinal glial cells that migrate through defects in the internal limiting membrane to proliferate and contract on the inner retinal surface [17-19]. The pathogenesis of macular edema in idiopathic ERM has not been well studied. Increases in the macular thickness in patients with ERM could be considered the result of deformation of the neurosensory retina by mechanical traction or macular edema caused by a breakdown of the blood-retinal barrier [20]. Mandelcorn et al. [21] demonstrated that VEGF and transforming growth factor- $\beta$ have been found in idiopathic ERM, and that these growth factors correlated with the degree of the breakdown of the blood-retinal barrier in the fluorescein angiogram. Therefore, bevacizumab might work as an anti-VEGF agent to somewhat reduce macular edema caused by a biochemical pathway, which is believed to play a minor role in the pathogenesis of idiopathic ERM [12].

From the literature review, there were several reports regarding the correlation between foveal thickness and visual acuity [16, 22-25]. Some authors reported that there was no correlation between visual acuity and foveal thickness after surgery [22, 23], whereas others reported that visual acuity was well correlated with foveal thickness $[16,24,25]$. In our study, baseline and postoperative foveal thickness were found to be well correlated with visual outcome in both the treatment and control groups.

In summary, postoperative visual improvement of idiopathic ERM is favorable, as a stable vision is usually achieved approximately 9 months after PPV.

The final BCVA was correlated significantly with baseline CFT. Three consecutive IVB could reduce macular edema within the first 2 months after baseline but failed to significantly reduce CFT by the third injection. In our study, the long-term follow-up of final visual and anatomical outcome showed no significant difference between patients with or without IVB. Therefore, IVB may not be advocated as an effective treatment for this condition. 
Chang et al.: Long-Term Anatomical and Functional Outcome of Three IVB for Persistent Macular Edema after Idiopathic Macular ERM Peeling

\section{Acknowledgment}

The authors are grateful for the assistance from the Statistical Analysis Laboratory, Department of Medical Research, Chung-Ho Memorial Hospital, Kaohsiung Medical University.

\section{Disclosure Statement}

No conflicting relationships exist for any of the authors.

\section{References}

1 Johnson TM, Johnson MW: Epiretinal membrane; in Yanoff M, Duker JS (eds): Ophthalmology, ed 3. Elsevier, 2004, pp 686-687.

2 Machemer R: The surgical removal of epiretinal macular membranes. Klin Monbl Augenheilkd 1978;173:36-42.

-3 Margherio RR, Cox MS Jr, Trese MT, Murphy PL, Johnson J, Minor LA: Removal of epimacular membranes. Ophthalmology 1985;92:1075-1083.

4 de Bustros S, Thompson JT, Michels RG, Rice TA, Glaser BM: Vitrectomy for idiopathic epiretinal membranes causing macular pucker. Br J Ophthalmol 1988;72:692-695.

-5 Lee PY, Cheng KC, Wu WC: Anatomic and functional outcome after surgical removal of idiopathic macular epiretinal membrane. Kaohsiung J Med Sci 2011;27:268-275.

-6 Cheng KC, Wu WC, Chen KJ: Intravitreal triamcinolone acetonide vs bevacizumab for treatment of macular oedema secondary to branch retinal vein occlusion. Eye 2009;23:2023-2033.

-7 Wu WC, Cheng KC, Wu HJ: Intravitreal triamcinolone acetonide vs bevacizumab for treatment of macular oedema due to central retinal vein occlusion. Eye 2009;23:2215-2222.

8 Kovach JL, Rosenfeld PJ: Bevacizumab (avastin) therapy for idiopathic macular telangiectasia type II. Retina 2009; 29:27-32.

-9 Nicholson BP, Schachat AP: Review of clinical trials of anti-VEGF agents for diabetic retinopathy. Graefes Arch Clin Exp Ophthalmol 2010;248:915-930.

10 Chen CH, Wu PC, Liu YC: Intravitreal bevacizumab injection therapy for persistent macular edema after idiopathic macular epiretinal membrane surgery. J Ocul Pharmacol Ther 2011;27:287-292.

-11 Fine HF, Iranmanesh R, Iturralde D, Spaide RF: Outcomes of 77 consecutive cases of 23-gauge transconjunctival vitrectomy surgery for posterior segment disease. Ophthalmology 2007;114:1197-1200.

12 Konstantinidis L, Berguiga M, Beknazar E, Wolfensberger TJ: Anatomic and functional outcome after 23-gauge vitrectomy, peeling, and intravitreal triamcinolone for idiopathic macular epiretinal membrane. Retina 2009;29: 1119-1127.

-13 Konstantinidis L, Uffer S, Bovey EH: Ultrastructural changes of the internal limiting membrane removed during indocyanine green assisted peeling versus conventional surgery for idiopathic macular epiretinal membrane. Retina 2009;29:380-386.

14 Lai CC, Wang NK, Wu WC, Yeung L, Hwang YS, Chen KJ, Chen TL, Chuang LH: The long-term anatomical and visual effect of intravitreal triamcinolone injection during vitrectomy for the treatment of idiopathic macular epiretinal membrane. Cutan Ocul Toxicol 2011;30:292-297.

15 Treumer F, Wacker N, Junge 0, Hedderich J, Roider J, Hillenkamp J: Foveal structure and thickness of retinal layers long-term after surgical peeling of idiopathic epiretinal membrane. Invest Ophthalmol Vis Sci 2011;52:744-750.

16 Kim J, Rhee KM, Woo SJ, Yu YS, Chung H, Park KH: Long-term temporal changes of macular thickness and visual outcome after vitrectomy for idiopathic epiretinal membrane. Am J Ophthalmol 2010;150:701-709.

-17 Roth AM, Foos RY: Surface wrinkling retinopathy in eyes enucleated at autopsy. Trans Am Acad Ophthalmol Otolaryngol 1971;75:1047-1058.

18 Foos RY: Vitreoretinal juncture; epiretinal membranes and vitreous. Invest Ophthalmol Vis Sci 1977;16:416-422. Bellhorn MB, Friedman AH, Wise GN, Henkind P: Ultrastructure and clinicopathologic correlation of idiopathic preretinal macular fibrosis. Am J Ophthalmol 1975;79:366-373.

20 Ahn JH, Park HJ, Lee JE, Oum BS: Effect of intravitreal triamcinolone injection during vitrectomy for idiopathic epiretinal membrane. Retina 2012;32:892-896.

-21 Mandelcorn E, Khan Y, Javorska L, Cohen J, Howarth D, Mandelcorn M: Idiopathic epiretinal membranes: cell type, growth factor expression, and fluorescein angiographic and retinal photographic correlations. Can J Ophthalmol 2003;38:457-463.

22 Kwon SI, Ko SJ, Park IW: The clinical course of the idiopathic epiretinal membrane after surgery. Korean J Ophthalmol 2009;23:249-252.

23 Massin P, Allouch C, Haouchine B, Metge F, Paques M, Tangui L, Erginay A, Gaudric A: Optical coherence tomography of idiopathic macular epiretinal membranes before and after surgery. Am J Ophthalmol 2000;130:732-739.

24 Ishida M, Takeuchi S, Nakamura M, Morimoto K, Okisaka S: The surgical outcome of vitrectomy for idiopathic epiretinal membranes and foveal thickness before and after surgery (in Japanese). Nippon Ganka Gakkai Zasshi 2004;108:18-22.

25 Hassenstein A, Scholz F, Richard G: OCT in epiretinal gliosis. Ophthalmologe 2005;102:127-132. 